\title{
REVISTA
}

\section{RELAÇÃO ENTRE OS PERFIS DE INVESTIDORES, PRODUTOS FINANCEIROS E RISCOS NO MERCADO FINANCEIRO BRASILEIRO}

\author{
RELATIONSHIP BETWEEN INVESTOR PROFILE, FINANCIAL \\ PRODUCTS AND BRAZILIAN FINANCIAL MARKET
}

\author{
${ }^{1}$ Adriano Bonela Sarti*. \\ ${ }^{2}$ Igor Meireles de Oliveira. \\ ${ }^{3 *}$ Lucas Marin Bessa.

\begin{abstract}
${ }^{1}$ Instituto Federal do Espírito Santo - Campus Venda Nova do Imigrante. E-mail: adrianobonelasarti@gmail.com

${ }^{2}$ Instituto Federal do Espírito Santo - Campus Venda Nova do Imigrante. E-mail: igormeirelesdeoliveira@gmail.com

${ }^{3}$ Instituto Federal do Espírito Santo - Campus Venda Nova do Imigrante. E-mail: lucas.bessa@ifes.edu.br

*Autor de correspondência
\end{abstract}

Artigo submetido em 12/05/2020, aceito em 21/12/2020 e publicado em 28/12/2020.

Resumo: Este artigo tem por objetivo descrever a relação entre os principais perfis de investidores, os produtos financeiros disponíveis no mercado brasileiro e seus respectivos riscos. A metodologia adotada baseia-se em pesquisa bibliográfica. Elaborou-se um quadro contendo a descrição dos perfis de investidores, sua exposição a risco e relacionando-os com produtos financeiros disponíveis no mercado brasileiro. Concluiu-se que existem produtos financeiros mais adequados para cada perfil de investidor e que os investidores tendem a compartilhar características comuns, dentre elas: percepção a risco, prazos e retornos esperados.

Palavras-chave: perfis de investidores; tolerância a riscos; produtos financeiros; educação financeira.

\begin{abstract}
This article aims to describe the relationship between the profiles of investors, the financial products available in the Brazilian market and their risks. The methodology is based on bibliographic research. A table was prepared containing the description of some investment profiles, their exposure to risks and relating them to financial products for each investor profile and that investors tend to share common characteristics, among them: perception of risk, terms end expected returns.
\end{abstract}

Keywords: investors profile; risk tolerance; financial products; financial education.

\section{INTRODUÇÃO}

Apesar de abordarem o tema diversos meios de investimentos atualmente, sejam nas mídias sociais, jornais e canais televisivos, pouco se discute quanto a questões sobre o risco 
envolvido nos investimentos, o perfil de investidores e os produtos financeiros que melhor se adequam para cada indivíduo.

Segundo Padoveze (2010), investimento caracteriza-se como "um gasto não consumido imediatamente cujos resultados virão dos resultados futuros desse gasto". Para Hoji (2014), investimento é "uma aplicação de dinheiro em títulos, ações, imóveis, maquinários, entre outros, com intuito de obter lucro".

Partindo da premissa de que há inúmeros produtos financeiros disponíveis no mercado, o investidor, seja ele pessoa física ou jurídica, depara-se com variáveis, como gerenciamento de riscos, expectativas futuras, riscos incidentes no produto, entre outros fatores (SANTOS, 2005). Para Augusto e Freire (2014), essas são algumas variáveis que levam o investidor a delimitar quais produtos financeiros melhor se encaixam ao seu perfil.

Visando avaliar a necessidade de um conhecimento prévio acerca de características pessoais no que diz respeito a investimento, para que o investidor possa tomar decisões com relação à alocação de suas reservas, este artigo tem por objetivo descrever a relação entre os perfis de investidores, os produtos financeiros disponíveis no mercado e seus respectivos riscos. Os assuntos foram abordados nos resultados e discussões em cinco partes: fatores que influenciam a tomada de decisão de investir; risco e retorno em investimentos; perfis de investidores mais comuns no mercado financeiro; características gerais dos investidores e principais produtos financeiros e; perfis de investidor $\mathrm{x}$ exposição a risco $\mathrm{x}$ tipos de investimento. Por fim, é proposto um quadro visando facilitar a visualização dessa relação e auxiliar na tomada de decisão de cada indivíduo.

\section{REFERENCIAL TEÓRICO}

A história do homem é marcada por inúmeros estudos, registros e princípios que atuam como intermediador das interações humanas (BARROS, 2006). Um desses intermediadores atua no âmbito econômico, trazendo à tona os valores dos objetos, bem como seus meios e fins para efetuar tal troca.

Atualmente, vivemos em um Sistema Econômico denominado Capitalismo, no qual sua principal característica é a acumulação de capital (CARCANHOLO, 2011). Essa relação de acumulação de capital, proposta pelo Capitalismo, faz com que a sociedade moderna busque meios e alternativas para cumprir tal característica. Alguns produtos foram criados e estão atualizando-se conforme o desenvolvimento tecnológico e a necessidade dos indivíduos que necessitam decidir entre vários serviços das instituições financeiras (financiamento, cartão de crédito, consórcio e outros), empreender, planos de aposentadoria, como e por que poupar, além também de como investir (AMADEU, 2009).

O Sistema Capitalista ganhou destaque no século XIX e XX, com o advento da globalização. Apesar de a característica desse sistema ser a produção em escala, comércio e enriquecimento, isso proporciona fatores de riscos, como, por exemplo, colapsos econômicos, como a vivida em 1929, que ficou conhecida como "a grande depressão", a do petróleo em 1973 e a imobiliária em 2008, gerando insegurança tanto para os indivíduos quanto para o governo, além da desvalorização da moeda local, desemprego etc. (COMPARATO, 2017). Júnior e Teixeira (2019) acrescentam que essas crises e ditaduras políticas, dentre outros fatores, levaram a República a incertezas.

As incertezas políticas e crises tendem a gerar resultados negativos para a economia, como a inflação, que, de acordo com Simonsen (1985), é o aumento 
contínuo e generalizado dos preços dos produtos. Quando descontrolada, pode gerar desconforto para a população, pois a moeda, seu principal meio de troca, começa a desvalorizar-se perante o preço dos produtos (LOPES, 1984).

Não somente a população passava por dificuldades financeiras nesse período, o governo brasileiro também enfrentou durante meados do século XX dificuldade em relação a sua dívida externa, pois na posição de grande importador de petróleo e a alta do preço, fez com que sua dívida externa aumentasse consideravelmente (CERQUEIRA, 2003).

Em 1994, com a implantação do Plano Real, o Brasil observou uma revolução financeira, pois a estabilidade econômica proporcionou inúmeros fatores positivos, como o aumento do poder aquisitivo da moeda e controle inflacionário por meio de mecanismos financeiros (DA SILVA; DA SILVA MACEDO, 2009). Com isso, o Plano obteve sucesso na redução da inflação, que, em suma, foi um dos principais problemas econômicos dos anos 80 e 90 no país (DA SILVEIRA, 2005).

Acompanhando esses movimentos, o mercado também está em constante evolução, bem como os produtos financeiros, tornando-se cada vez mais sofisticados (ROQUETTE; LAUREAN; BOTELHO, 2014)

Os produtos financeiros, o dinheiro e as demais ferramentas são interpretadas como um intermediador entre o homem e seus desejos, possuindo, assim, significados diferentes a cada indivíduo e despertando motivações distintas (MONTEIRO et al., 2011). Essa forma de intermediação pode ser uma ferramenta relevante para a vida do cidadão, pois poderá auxiliá-lo em suas realizações no âmbito financeiro.

O Brasil possui o maior e mais complexo mercado financeiro da América Latina, composto por inúmeras instituições bancárias e financeiras, Caixas Econômicas, agentes normativos e de supervisão (FILHO, 1999). Tal mercado foi posto em prova, pois era necessário que as empresas, principalmente, as instituições financeiras e pessoas físicas se adequassem às novas diretrizes da economia pós Plano Real, como maior volume de capital estrangeiro, estipulação de metas para controle inflacionário, moeda forte perante as principais moedas internacionais, abertura de mercado e outros fatores até então pouco comuns na economia brasileira (CARVALHEIRO, 2002).

Enfrentamos hoje um grande ponto de inflexão no qual o modelo educacional proposto no Brasil apresenta falhas, como a deficiência por parte dos estudantes no quesito manuseio de suas economias para seu futuro financeiro (DOS SANTOS et al, 2017). A educação financeira entra como uma ferramenta para auxiliar a tomada de decisão e o controle dos ganhos e gastos financeiros. Augustins, Costa e Barros (2012) descrevem a educação financeira como sendo um processo de aprendizado por meio de informações de instruções e de conselhos, que auxilia na compreensão acerca de conceitos e de produtos financeiros, além de desenvolver competências e confiança para lidar com os riscos e oportunidades inerentes ao lidarem com recursos financeiros.

\section{PROCESSOS METODOLÓGICOS}

Para o desenvolvimento do estudo foram realizadas pesquisas científicas nas plataformas Google Scholar, SciELO e Portal de Periódicos Capes, sendo esta uma pesquisa caracterizada como qualitativa, realizada entre agosto de 2019 e março de 2020.

Com base em pesquisas bibliográficas, foi elaborado um quadro, contendo a descrição de alguns perfis de investimento, sua exposição a risco e relacionando-os com alguns produtos 
financeiros disponíveis no mercado brasileiro.

Essa pesquisa faz parte das discussões do Grupo de Pesquisa em Educação Financeira (GPEFIN) criado com intuito de pesquisar questões relacionadas à Educação Financeira, Alfabetização Financeira e investimentos, desenvolvido por estudantes do Curso Bacharelado em Administração, um professor de finanças e uma psicóloga, todos vinculados ao Ifes Campus Venda Nova do Imigrante.

\section{RESULTADOS E DISCUSSÃO}

Acompanhando a metodologia proposta, dividimos os assuntos em cinco partes: (1) fatores que influenciam a tomada de decisão de investir - nesta parte discutimos quanto aos fatores que influenciam o investidor em sua tomada de decisão; (2) risco e retorno em investimentos - aqui é apresentamos a relação entre risco e retorno nos investimentos e sua importância; (3) perfis de investidores mais comuns no mercado financeiro - nesta parte, demonstramos os diferentes tipos de perfil de investidor e seus níveis de aversão a risco; (4) características gerais dos investidores e principais produtos financeiros - aqui apresentamos os tipos de investimento mais comuns disponíveis no mercado brasileiro; (5) perfis de investidor $\mathrm{x}$ exposição a risco x tipos de investimento nesta parte, estabelecemos a relação entre as características estudadas que serviu de base para a criação de um quadro que resume os achados do presente estudo.

\subsection{FATORES QUE INFLUENCIAM A TOMADA DE DECISÃO DE INVESTIR}

Investimento no mercado financeiro é todo tipo de aplicação de algum ativo financeiro em busca de retornos futuros, seja por meio de dividendos, valorização das ações adquiridas ou rentabilidade atrelada a taxas (SOARES, 2015).

No mercado financeiro existem inúmeras opções de investimento que se adequam a cada perfil de investidor, partindo de renda fixa com aspectos gerais mais voltadas para o conservadorismo, ou seja, riscos controlados e rentabilidade conhecida, até à renda variável em que é possível obter altos ganhos, com maiores exposições a risco (OLIVEIRA, 2019).

Avaliar os riscos dos produtos de investimentos é necessário para que seja possível a melhor tomada de decisão. Aldatz e Júnior (2013) descrevem que o risco se dá quando existem informações passadas sobre a decisão, porém os resultados futuros estão sujeitos à mudanças. Os autores também apontam o risco como sendo um dos fatores de impacto na hora da tomada de decisão, sendo a análise de risco uma das técnicas de análise de decisão em investimentos. De Anhaia (2006) descreve o risco como a incerteza sobre $o$ futuro ligado à possibilidade de ganho ou perda na aplicação.

De acordo com o Banco Central do Brasil (2013), são delimitados três grandes fatores comumente levados em conta pelos investidores, (a) liquidez, atrelado à capacidade de transformar o ativo em dinheiro; (b) o risco, diretamente ligado à capacidade de acarretar retornos diferentes do esperado; e (c) a mensuração de rentabilidade, ligado ao retorno esperado do investimento.

No mercado financeiro existem inúmeras aplicações com características de prazos distintas, desde as com liquidez diária, ou seja, aquela que pode ser resgatada no momento que o investidor desejar, como a poupança, atém aplicações que demoram anos para serem resgatados, como é o caso de alguns Certificados de Depósito Bancário (CDB) com altos prazos de vencimento. 
O investidor deve ter em mente que o mercado financeiro possui inúmeros riscos e, por meio da diversificação do portfólio e período de investimento, essa correlação risco e retorno pode se minimizar, ou seja, o investidor estará exposto a menores riscos com maiores possibilidades de ganhos (RENNER, 2010).

\subsection{RISCOS E RETORNO EM INVESTIMENTOS}

Com o passar do ciclo econômico, a taxa de referência, ou seja, o Sistema Especial de Liquidação e Custódia (Selic), tende a ser atualizada para que melhor se adeque ao momento econômico. Sendo assim, em momento no qual a população está com alto consumo e os preços estão aumentando de forma generalizada, tem-se a intervenção do Banco Central, por intermédio do Comitê de Política Monetária (COPOM), modificando a taxa, aumentando-a fazendo com que haja o controle da inflação, ou diminuindo-a, para que haja incentivo ao consumo (OLIVEIRA et al., 2018). Essa taxa, a Selic, também é uma das principais referências quanto à remuneração de investimentos em renda fixa.

Em caso de variação negativa dessa taxa, alguns investidores se expõem mais ao risco, direcionando, assim, parte de seus recursos para renda variável, a fim de obter maiores possibilidade de retorno (ZIMNOCH, 2012).

Para Gitman e Zutter (2017), retorno é o ganho ou a perda total que se observa em um período de tempo. Esse retorno pode ser variável, caso haja aplicação em renda variável ou fixa, advindo de investimentos em renda fixa.

Visando auxiliar os investidores a melhor delimitar o risco e retorno, ao decorrer do tempo, foram desenvolvidas ferramentas. A partir de 1952, diversos estudos desenvolvidos resultaram em um modelo para mensurar o retorno ou risco de um ativo chamado Capital Asset Pricing Model (CAPM) ou Modelo de Precificação dos Ativos Financeiros, sendo este um dos mais utilizado no meio acadêmico e empresarial pela sua simplicidade teórica e prática (TEIXEIRA; DA CUNHA, 2017).

No mercado de ações existem dois tipos mais comuns de análise que, também, servem como ferramentas para apoiar a tomada de decisão do investidor: análise fundamentalista e análise técnica. O termo análise técnica compreende uma ampla análise de fatores e indicadores. Exemplo disso são padrões nos gráficos gerados durante as negociações nos pregões que indicam aumento ou queda no preço das ações negociadas, e os analistas ou também conhecidos como grafistas, aproveitam esses momentos para gerar ganho de capital (DE CARVALHO; DA COSTA; DE OV GOULART, 2008).

A Bolsa de Valores pode ser definida como um conjunto de empresas cotadas que buscam captação de recursos através da negociação de suas cotas, para que possam se desenvolver utilizando os investimentos obtidos (SANTOS, 2019).

Já a análise fundamentalista é um dos métodos de decisão de investimento utilizado há décadas e que visa à avaliação de uma empresa através de suas demonstrações contábeis e financeiras, bem como projeções de mercado e macro economia do país (TAVARES, 2012). Na Bolsa de Valores Brasileira (B3), os balanços contábeis são divulgados, normalmente, a cada três meses e regulados criteriosamente pela Comissão de Valores Monetários (CVM), um órgão regulador independente.

Esses são alguns instrumentos que possibilitam delimitar os riscos em determinado produto financeiro e, com isso, entender se o produto financeiro está adequado para a propensão a correr riscos por parte do investidor, alinhado com seu perfil. 


\subsection{OS PERFIS DE INVESTIDORES MAIS COMUNS NO MERCADO FINANCEIRO}

Em uma abordagem mais clássica de perfil de investidor, Graham (2016) define que há dois tipos: os investidores defensivos, que são aqueles que compram fundos de investimentos consolidados no mercado, para que sua exposição ao risco seja baixa; e os investidores empreendedores, que são aqueles que se expõem a maiores riscos buscando retorno maiores que os investidores defensivos.

Cada investidor apresenta um perfil com estratégias, tolerância a risco, objetivos, permanência no investimento, dentre outras variáveis (RAMBO, 2014). Esses são fatores chaves para geração de rentabilidade no mercado financeiro. $\mathrm{Na}$ literatura científica moderna atual, tem-se a delimitação de três grandes grupos de investidores, com objetivos e aceitação de riscos distintos uns dos outros. Os grupos de investidores podem ser definidos como: conservadores, moderados e agressivos (HAUBERT; DE LIMA; HERLING, 2012); (CADORE, 2007); (DE ALMEIDA, 2017).

\subsection{CARACTERÍSTICAS GERAIS DOS INVESTIDORES E PRINCIPAIS PRODUTOS FINANCEIROS}

Com novas políticas econômicas vigentes no Brasil e o controle inflacionário, por meio das metas de inflação estipuladas pelo Conselho Monetário Nacional $(\mathrm{CMN})$ e a intervenção do Banco Central do Brasil (BACEN), por meio do COPOM, foi possível para os investidores terem um referencial em suas aplicações financeiras em renda fixa através da Taxa Selic, o indexador atrelado à remuneração de títulos públicos federais e alguns produtos de instituições privadas (OLIVEIRA et al., 2018).

Além das aplicações atreladas à Selic, algumas instituições e o próprio
Governo Federal emitem títulos de investimentos com taxas pré-fixadas, ou seja, o investidor saberá no momento da aquisição do título qual será sua remuneração (CARVALHEIRO, 2002). No caso dos títulos do Governo Federal, Tesouro Nacional, há cinco tipos de títulos oferecidos: Tesouro Selic, Tesouro Prefixado, Tesouro Prefixado com juros semestrais, Tesouro IPCA (esse indexador utilizado como indicador da inflação) e o Tesouro IPCA com juros semestrais (TESOURO DIRETO, 2020).

No mercado financeiro e de capitais existem incontáveis opções de investimento, como a caderneta de poupança, que apresenta risco mínimo para o poupador além de uma garantia de rentabilidade, com baixo risco, e o mercado de renda variável que engloba desde ações até criptomoedas, influenciando na cotação diária, tornando altamente exposto, arriscados e voláteis (COSTA; DA CRUZ, 2016). Observa-se que a poupança, em momentos de alta inflação, pode ter ganho real negativo.

Investidores conservadores tendem a aportarem parte de seu capital em investimentos, como a poupança, Certificados de Depósito Bancário, de instituições consolidadas e com credibilidade que possuem alta capacidade de pagamento (SILVA et al., 2008).

Alguns investimentos com características conservadoras possuem garantia do Fundo Garantidor de Crédito (FGC), criado com base na Resolução $\mathrm{n}^{\circ}$ 2.211/95, na qual garante que, caso a instituição financeira entre em estado de falência, ela irá restituir o valor investido em até 250 mil reais por CPF e instituição financeira. Alguns títulos, de acordo com o FGC (2017) são: Certificados de Depósitos Bancários, Poupança, Letras de Crédito Imobiliário (LCI), dentre outros títulos de renda fixa.

Alguns dos principais títulos de renda fixa, de acordo com CVM (2017), são: os CDBs, que são títulos emitidos por 
bancos comerciais ou múltiplos com objetivo de captar recursos para financiar as atividades de crédito; as LCI, que são também emitidos por bancos e dizem respeito a títulos de créditos para financiamento imobiliário; e a poupança, que possui rentabilidade mensal e liquidez diária.

Os títulos públicos são também uma alternativa para os investidores. De acordo com Hoji (2014), os Títulos Públicos Federais são emitidos em nome do Tesouro Nacional ou do Banco Central. Esses títulos são os financiamentos das dívidas da União, sendo assim, ao adquirir tais títulos, o investidor está emprestando dinheiro ao governo e, em contrapartida, recebendo rendimentos (PIMENTEL et al., 2015). Essa aplicação é emitida pelo Governo Federal, por intermédio da Tesouraria, e possui garantia do Governo Federal em recomprá-la a qualquer momento (BONAPAZ, 2019).

De Acordo com o Tesouro Direto (2020), os Títulos Públicos Federais são uma alternativa para os investidores que buscam segurança e rentabilidade, pois além da garantia da recompra pelo governo, esses investimentos tornam-se ideal para aqueles que buscam retornos minimamente superiores à inflação, bem como segurança para seus investimentos, sendo estes mais adequados a investidores que possuem perfil conservador.

Em momentos em que a taxa básica de juros está relativamente baixa para incentivo econômico e o consumo, os investidores, sejam eles institucionais ou pessoas físicas, tendem a correr riscos controlados para obterem retornos maiores que os obtidos em títulos de renda fixa (ZIMNOCH, 2012).

Investidores que buscam maiores retornos, porém sem tanta exposição ao risco, possuem características moderadas, aportam recursos em produtos com maiores possibilidade de retorno se comparado aos investimentos conservadores (VELHO, 2010). Nesse momento, investimentos como Debêntures são uma alternativa para o investidor, pois trata-se de um título de renda fixa utilizado pelas empresas para captarem recursos e, em contrapartida, oferecem maior rentabilidade advinda do maior risco de crédito, porém sem garantias do FGC, apenas do emitente (MARQUES, 2014).

Assim como as Debêntures, os Fundos de investimentos também ganham destaque para investidores com perfil moderado. De acordo com Hoji (2014), os fundos de investimentos são serviços prestados por uma instituição financeira especializada que, em contrapartida, cobram uma taxa de administração. Essa captação ocorre por intermédio da aplicação financeira dos cotistas. Existem fundos de investimentos que podem aportar, de acordo com seu regulamento, em ações, multimercado e de investimento de longo prazo (VELHO, 2010).

Os fundos de investimentos podem utilizar benchmarks, ou seja, parâmetros de investimentos que os distingue. De acordo com Filho e De Sousa (2015), existem fundos de investimentos que utilizam alavancagem, ou seja, utilizam produtos como derivativos, que podem resultar em perdas superiores ao patrimônio líquido, possuindo, assim, considerável grau de risco. Também são conhecidos como Fundos de Investimento de Alto Risco. Já para a CVM (2014), existem Fundos de Renda Fixa que alocam, pelo menos, $80 \%$ do patrimônio líquido em investimentos de renda fica, desde Títulos do Tesouro Direto, com baixa exposição ao risco até em Debêntures, com média exposição ao risco (CVM, 2014).

Os Fundos de Investimentos Imobiliários também são uma alternativa para investidores com perfil Moderado. Criado com base na lei n 8668 de 1993 e tendo como órgão regulador a CVM, os Fundo de Investimentos Imobiliários são um condomínio de pessoas de aplicam seus recursos em empreendimento imobiliários, concluídos ou em construção 
(COSENTINO; ALENCAR, 2011). Essa aplicação visa à obtenção de lucros por meio de dividendos por parte do fundo, sejam eles mensais, trimestrais ou anuais.

Há ainda investidores com perfil Agressivo, ou seja, aqueles que tendem a agir como especuladores, alocando grande parte de seu patrimônio em investimentos com alto grau de risco, como ações e derivativos (HAUBERT; DE LIMA; HERLING, 2012). Esses investimentos normalmente são negociados na Bolsa de Valores, no caso do Brasil, na Bolsa de Valores oficial do Brasil (B3), sendo resultado da junção da Bolsa de Valores, Mercadorias e Futuros de São Paulo (BM\&F Bovespa) com a Central de Custódia e Liquidação Financeira de Títulos Privados (CETIP) e pelo Conselho Administrativo de Defesa Econômica (CADE).

Os investidores que possuem características agressivas, normalmente alocam seu capital em produtos altamente rentáveis, podendo multiplicar em várias vezes o capital próprio, como é o caso de alavancagem financeira, que significa a possibilidade de os acionistas da empresa obterem maiores lucros para suas ações com o uso mais intensivo de capital de terceiros, ou seja, empréstimos que são utilizados para negociar produtos $\mathrm{e}$ efetuarem day e swing trade (PADOVEZE, 2010).

Além da alavancagem financeira, existe também o mercado de derivativos de crédito. De acordo com Aronovich e Pereira (2003), esse instrumento concede ao investidor maior poder de alavancagem, visto que essa ferramenta derivada de benchmarks. De acordo com a CVM (2020), os derivativos são contratos padronizados previamente, possuindo prazos, quantidade, dentre outros fatores específicos no momento da aquisição. Essa derivação possibilita lucros exponenciais ou também perdas superiores ao patrimônio. Outro produto que investidores tendem a portar seus recursos são criptomoedas, que possuem inúmeros fatores que influenciam na cotação, gerando, assim, elevado risco com alta possibilidade de retorno.

\subsection{PERFIS DE INVESTIDOR $X$ EXPOSIÇÃO A RISCO $X$ TIPOS DE INVESTIMENTOS}

Com base no referencial teórico, elaboramos um quadro visando demonstrar a relação entre o perfil do investidor, o grau de exposição a risco e os tipos de investimentos mais adequados.

Quadro 1: Relação Perfil x Exposição a Risco x Tipo de Investimento

\begin{tabular}{|c|c|c|}
\hline $\begin{array}{l}\text { Perfil do } \\
\text { Investidor }\end{array}$ & $\begin{array}{c}\text { Exposição } \\
\text { ao Risco }\end{array}$ & $\begin{array}{c}\text { Tipo de } \\
\text { Investimento } \\
\end{array}$ \\
\hline Conservador & Baixa & $\begin{array}{c}\text { Poupança; } \\
\text { CDB e RDB; } \\
\text { LCI; Tesouro } \\
\text { Selic; Fundos } \\
\text { de } \\
\text { Investimento } \\
\text { em renda fixa, } \\
\text { Imóveis. }\end{array}$ \\
\hline Moderado & Média & $\begin{array}{c}\text { Fundos de } \\
\text { Investimento } \\
\text { multimercado; } \\
\text { Fundos de } \\
\text { Investimento } \\
\text { Imobiliários. }\end{array}$ \\
\hline Agressivo & Alta & $\begin{array}{c}\text { Fundos de } \\
\text { Investimento } \\
\text { multimercado } \\
\text { e ações; Ações; } \\
\text { Criptomoeda; } \\
\text { Derivativos. }\end{array}$ \\
\hline
\end{tabular}

Fonte: Elaborada pelos autores.

Quanto ao perfil Conservador, aquele que tende a se expor de forma mínima ao risco, tem-se os seguintes ativos financeiros mais condizentes com seu perfil e objetivo: Poupança, CDB, RDB, LCI, Tesouro Selic, Fundos de Investimento com menos exposição a risco, dentre outros.

Já o perfil Moderado tende a se expor mais ao risco, em busca de maiores 
possibilidade de retorno, tendo como os seguintes produtos: Fundos de Investimento com maior exposição ao risco do que os utilizados para o perfil Conservador, Fundo Imobiliário e dentre outros.

Por fim, o investidor Agressivo busca maiores possibilidade de retorno através de produtos financeiros com maiores exposições ao risco, normalmente de renda variável, como: Fundos de Investimentos de maior risco com maior parte de sua carteira em renda variável, Ações, Câmbio, Derivativos; dentre outros.

\section{CONCLUSÕES}

É fundamental para o investidor conhecer sua tolerância a risco, prazos de investimento e objetivos, para que melhor possa tomar decisões de investimento, gerando, assim, retornos esperados. Para auxiliar no conhecimento dos tipos de investimentos mais adequados para cada perfil, este estudo apresentou uma proposta de quadro demonstrando a relação entre os produtos financeiros e os riscos que cada um possui, bem como sua relação com o perfil.

Concluímos que cada investidor deve estabelecer ferramentas básicas para auxiliar suas tomadas de decisão, sejam elas voltadas para renda fixa ou variável, como a análise técnica e análise fundamentalista, bem como modelos para análise de investimentos visando maximizar suas posições, sejam elas em produtos financeiros de maior risco, sejam para escolha de ativos de baixo risco como os títulos de renda fixa.

A educação financeira, também, mostra-se como algo crucial para o desenvolvimento do investidor para que sua tomada de decisão seja racional, sustentável e munida de todas informações necessárias auxiliando para que todos objetivos pessoais e profissionais sejam alcançados.

\section{AGRADECIMENTOS}

Agradecemos ao Instituto Federal do Espírito Santo por ceder estrutura e apoio para o desenvolvimento desta pesquisa e dos trabalhos do Grupo de Pesquisa em Educação Financeira (GPEFIN).

\section{REFERÊNCIAS}

ALDATZ, Ramiro Jorge; JÚNIOR, Melquiades Pereira de Lima. Análise de Investimento do Segmento de transporte em Condições de Incerteza e Risco.

Revista Ambiente Contábil - UFRN Natal-RN. v. 5. n. 1, p. $224-240$, jan./jun. 2013. Disponível em: https://periodicos. ufrn.br/ambiente/article/view/3325/2702 Acesso em: 23 jul. 2019.

\section{AMADEU, João Ricardo. A educação} financeira e sua influência nas decisões de consumo e investimento: proposta de inserção da disciplina na matriz curricular. Maio, 2009. Disponível em: http://livros01. livrosgratis.com.br/cp150820.pdf. Acesso em: 13 jan. 2020.

AUGUSTO, Mário António Gomes; FREIRE, Sara Filipa Rodrigues. Atributos do investidor e tolerância face ao risco: a perspectiva dos pequenos investidores. REGE-Revista de Gestão, v. 21, n. 1, p. 103-120, 2014. Disponível em: https:// pdfs.semanticscholar.org/1fb6/3fef3c329af c67fb5e94999536c12a285e55.pdf. Acesso em: 13 jan. 2020.

Banco Central do Brasil (BACEN). Caderno de Educação Financeira Gestão de Finanças Pessoais. Disponível em: https://www.bcb.gov.br/content/ cidadaniafinanceira/documentos_cidadania /Cuidando_do_seu_dinheiro_Gestao_de_Fi nancas_Pessoais/caderno_cidadania_financ eira.pdf. Acesso em: 05 fev. 2020.

BONAPAZ, Vinicius. Fundo de investimento ou títulos públicos: uma 
análise comparativa da rentabilidade para o perfil de investidor conservador de 2016 a 2018. Trabalho de Conclusão de Curso Universidade de Caxias do Sul, Caxias do Sul 2019. Disponível em: https:// repositorio.ucs.br/xmlui/bitstream/handle/1 1338/5053/TCC\%20Vin\%c3\%adcius\%20 Bonapaz.pdf? sequence $=1 \&$ isAllowed $=\mathrm{y}$. Acesso em: 15 out. 2019.

BARROS, José D.'Assunção. História, espaço e tempo. Interações necessárias. Varia história, v. 22, n. 36, p. 460-475, 2006. Disponível em: https://www.scielo. br/pdf/vh/v22n36/v22n36a12.pdf. Acesso em: 16 dez. 2019.

\section{CAIXA ECONÔMICA FDERAL. Tipos de Investimentos Disponível em:} http://www.caixa.gov.br/educacaofinanceira/aulas-empresas/tipos-deinvestimento/Paginas/default.aspx. Acesso em: 01 mar. 2020.

\section{BANCO CENTRAL DO BRASIL.} Caderno de Educação Financeira Gestão de Finanças Pessoais. Brasília: BCB, 2013. 72 p. Disponível em: https://www.bcb.gov. br/content/ cidadaniafinanceira/documentos_cidadania /Cuidando_do_seu_dinheiro_Gestao_de_Fi nancas_Pessoais/caderno_cidadania_financ eira.pdf. Acesso em: 02 mar. 2019.

CADORE, Rosmari Bertolo. Perfil do investidor diante do portfólio de possibilidades para investimentos financeiros no Banco do Brasil agência de Xaxim SC. Trabalho de Conclusão de Curso - Universidade Federal do Rio Grande do Sul, Porto Alegre (RS) 2007. Disponível em: https://www.lume.ufrgs.br/ bitstream/handle/10183/14196/000649744. pdf? sequence $=1$. Acesso em: 14 nov. 2019 .

CARVALHEIRO, Nelson. A política monetária no Brasil pós-Real. Pesquisa \& Debate. Revista do Programa de Estudos Pós-Graduados em Economia Política, v. 13, n. 1 (21), 2002. Disponível em: http:// revistas.pucsp.br/rpe/article/view/12028/87 08. Acesso em: 19 abr.2019.

CARCANHOLO, Marcelo Dias. Conteúdo e forma da crise atual do capitalismo: lógica, contradições e possibilidades.

Revista Crítica E Sociedade, v. 1, n. 3, p. 73-84, 2011. Disponível em: http:// www.seer.ufu.br/index.php/criticasociedad e/article/view/14551/8279. Acesso em: 03 ago. 2019.

COMPARATO, Fábio Konder. A civilização capitalista. 2.ed: Editora Saraiva, 2017. Acesso em: 18 set. 2019.

COSTA, Helder Tonini; DA CRUZ, Sarah Aparecida. Tipos de Investimento: os investimentos mais realizados. In: II Congresso Internacional do Grupo Unis. Fundação de Ensino e Pesquisa do Sul de Minas, 2016. Disponível em: http:// 192. 100.247.84/handle/prefix/541. Acesso em: 19 out. 2019.

COSENTINO, Rafael Mario Sant'Anna; ALENCAR, Claudio Tavares. Fundos de Investimento Imobiliário: Análise do desempenho e comparação com USREITs, UK-REITs, G-REITs e SIIC. Latin American Real Estate Society (LARES), 2011. Disponível em: https://lares. architexturez.net/system/files/lares-2011511-751-2-RV.pdf. Acesso em: 28 ago. 2019.

CVM. Instrução CVM no 555, de 17 de dezembro de 2014. Disponível em: http: //www.cvm.gov.br/export/sites/cvm/legisla cao/instrucoes/anexos/500/inst555.pdf. Acesso em: 03 mar. 2020.

CVM. Introdução: O que são derivativos. Disponível em: https://www.investidor. gov.br/menu/menu_investidor/derivativos/ derivativos_introducao.htm. Acesso em: 03 mar. 2020.

CVM - Top analise de investimentos. Disponível em: https://www.investidor. gov.br/portaldoinvestidor/export/sites/porta 
ldoinvestidor/publicacao/Livro/livro_TOP _analise_investimentos.pdf. Acesso em: 09 abr. 2020 .

DA SILVA, Nívia Aguiar; DA SILVA MACEDO, Marcelo Alvaro. Avaliação do Desempenho dos Fundos de Investimento de 1995 a 2002: Comparando Instituições Nacionais e Estrangeiras. RIC - Revista de Informação Contábil - ISSN 1982-3967 Vol. 3, no 1, p. 16-39, Jan-Mar/2009. Disponível em: https://periodicos.ufpe. $\mathrm{br} /$ revistas/ricontabeis/article/view/7911/79 88. Acesso em: 13 jan. 2020.

DA SILVEIRA, Stefano José Caetano; OMAR, Benedetti; RATHMANN, Régis; CONCEIÇÃO, Octavio Augusto Camargo. Reavaliando os objetivos e os resultados do plano real. Análise - Revista de Administração da PUCRS, v. 16, n. 2, 2005. Disponível em: http://revistas eletronicas.pucrs.br/ojs/index.php/face/arti cle/view/275/224. Acesso em: $21 \mathrm{dez}$. 2019.

DE ALMEIDA, André Luís Fernandes. Estudo do mercado brasileiro de renda fixa e o perfil do investidor brasileiro. Tese de Doutorado - Universidade Federal do Rio de Janeiro, 2017. Disponível em: http://monografias.poli.ufrj.br/monografias /monopoli10020143.pdf. Acesso em: 12 nov. 2019.

DE ANHAIA, Artur Vitoriano Gaieski. Os Riscos Sobre Investimentos do Mercado Financeiro Brasileiro. Dissertação de Pós-Graduação, Universidade Federal do Rio Grande do Sul, Porto Alegre, 2006. Disponível em: https://lume.ufrgs.br/ bitstream/handle/10183/8800/000589309.p df? sequence $=1 \&$ isAllowed $=y$. Acesso em: 14 dez. 2019.

DE CARVALHO, Luis Gustavo Pinto; DA COSTA JR, Newton C.A.; DE O.V. GOULART, Marco Antônio. Análise técnica versus hipótese dos mercados eficientes: um estudo utilizando o indicador MACD. Revista Alcance, v. 15, n. 3, p. 398-416, 2008. Disponível em: https://siaiap32.univali.br/seer/index.php/ra /article/view/767/621. Acesso em: 03 nov. 2019.

DOS SANTOS, Bruna Neris; DA SILVA ASOO, Rafael; DE CARVALHO, Carolina Goulart. Educação Financeira Infantil: A construção de cidadãos conscientes. Revista Eletrônica Organizações e Sociedade, v. 5, n. 4, p. 116-126, 2017. Disponível em: http://revista.facfama.edu.br/index.php/RO S/article/view/243/200. Acesso em: 21 set. 2019.

FILHO, Antônio Alves. Adaptação estratégica ao processo de estabilização econômica decorrente do Plano Real: o caso do Sistema Financeiro BESC. Revista de Ciências da Administração, v. 1, n. 1, p. 9-21, 1999. Disponível em: https:// periodicos.ufsc.br/index.php/adm/article/vi ew/7997/7382. Acesso em: 08 ago. 2019.

FILHO, Bolivar Godinho de Oliveira; DE SOUSA, Almir Ferreira. Fundos de investimento em ações no Brasil: métricas para avaliação de desempenho. REGERevista de Gestão, v. 22, n. 1, p. 61-76, 2015. Disponível em: https://reader. elsevier.com/reader/sd/pii/S180922761630 0935 ? token $=60 \mathrm{BE} 2 \mathrm{CEE} 2 \mathrm{~B} 039107 \mathrm{~F} 1 \mathrm{~F} 3 \mathrm{E} 0$ EBA7952DE64F1BEB7631E76B45DB1B C8100DA184A143433473A59F68C2BF1 EEDBF8179AFAA. Acesso em: 13 jan. 2020.

Fundo Garantidor de Crédito (FGC).

Sobre a garantia FGC - garantia ordinária - até R \$ 250 mil Disponível em: https:// www.fgc.org.br/garantia-fgc/sobre-agarantia-fgc. Acesso em: 12 mar. 2020.

AUGUSTINIS, Viviane Franco; COSTA, Alessandra de Sá Mello da; BARROS, Denise Franca. Uma Análise Crítica do Discurso de Educação Financeira: por uma Educação para Além do Capital. Revista Adm.made, Rio de Janeiro, v. 16, n. 3, p.79-102, set. 2012. Disponível em: 
http://revistaadmmade.estacio.br/index.php /admmade/article/viewFile/553/291. Acesso em: 02 fev. 2020.

GRAHAM, Benjamin. O investidor inteligente. 1 ed Harper Collins Brasil, 2016. Acesso: 12 fev. 2020.

HAUBERT, Fabricio Luis Colognese; DE LIMA, Marcus Vinicius Andrade; HERLING, Luiz Henrique Debei. Finanças comportamentais: um estudo com base na teoria do prospecto e no perfil do investidor de estudantes de cursos stricto sensu da grande Florianópolis. Revista Eletrônica de Estratégia \& Negócios, v. 5, n. 2, p. 171-199, 2012. Disponível em: http://portaldeperiodicos.unisul.br/index.ph p/EeN/article/view/935/0. Acesso em: 07 dez. 2019.

HOJI, Masakazu. Administração Financeira na Prática: Guia para Educação Financeira Corporativa e Gestão Financeira Pessoal. 5 Edição. Atlas, 2014. Acesso em: 04 set. 2019

JÚNIOR, Antonio Gasparetto; TEIXEIRA, Wagner. 130 anos de República no Brasil: entre avanços e retrocessos. Locus-Revista de História, v. 25, n. 2, 2019. Disponível em: https://periodicos. ufjf.br/index.php/ locus/article/view/29147/19952. Acesso em: 09 out. 2019.

GITMAN, Lawrence J., ZUTTER, Chad J.. Princípios de administração financeira. 14 ed. - São Paulo: Pearson Education do Brasil, 2017. Acesso: 09 nov. 2019.

LOPES, Francisco. Inflação inercial, hiperinflação e desinflação: notas e conjecturas. Textos para discussão 77, Departamento de Economia, Pontifícia Universidade Católica do Rio de Janeiro, 1984. Disponível em: https:// www.econstor.eu/bitstream/10419/186325/ 1/td077.pdf. Acesso em: 15 nov. 2019.

MARQUES, Bruno da Costa. Fundos de renda fixa índices de preços: uma análise de desempenho frente às variações da taxa Selic no período 2011-2013. Trabalho de Conclusão de Graduação - Universidade do Rio Grande do Sul, Porto Alegre, 2014. Disponível em: https://www.lume. ufrgs. br/bitstream/handle/10183/116259/000953 625.pdf? sequence $=1$ \&isAllowed $=y$. Acesso em: 02 out. 2019.

MONTEIRO, Marion. Onde investir em 2001. Revista Conjuntura Econômica, v. 55, n. 2, p. 32-35, 2001. Disponível em: http://bibliotecadigital.fgv.br/ojs/index.php /rce/article/view/31290/30097. Acesso em: 09 out. 2019.

MONTEIRO, Danielli; PEÑALOZA, Verônica; PINHEIRO, Victor. A relação existente entre a atitude ao dinheiro e a orientação motivacional para o trabalho. EnANPAD XXXV Encontro da ANPAD, Rio de Janeiro, 2011. Disponível em: http://www.anpad.org.br/diversos/down_zi ps/58/EOR1566.pdf. Acesso em: 12 nov. 2019.

OLIVEIRA, Márcio Júnior de Sousa; ASSIS, Arthur Coelho Porchat; JÚNIOR, Pedro dos Santos Portugal; SILVA, Sheldon William; LEMES, Poliana Tomaz. Variação da taxa SELIC e a rentabilidade de fundos de investimentos referenciados: uma análise comparativa no período de 2013 a 2016. Brazilian Journal of Development, Curitiba, v. 4, n. 4, p. 14491463, jul./set. 2018. Disponível em: https://www.aedb.br/seget/arquivos/artigos 17/402525.pdf. Acesso em: 18 nov. 2019.

\section{OLIVEIRA, Jessé Hollas. Finanças}

pessoais -análise dos perfis de investidores e os investimentos mais adequados no mercado financeiro. Monografia apresentada como requisito para a obtenção do Grau de Bacharel em Ciências Contábeis da Universidade de Caxias do Sul, 2019. Disponível em: ago. de agosto de 2020.

PIMENTEL, Bárbara Costa; LOPES, Paloma de Lavor; ARAUJO, Filipe Otavio 
Braga; DE OLIVEIRA, Louise Antunes. Títulos Públicos: Uma alternativa de investimento com ganhos reais e seguro. Simpósio de excelência em gestão e tecnologia, 2015. Disponível em: https: //www.aedb.br/seget/arquivos/artigos 15/28 822325.pdf. Acesso em: 03 dez. 2019.

PADOVEZE, Clóvis Luiz. Introdução à Administração Financeira. $2^{a}$ Edição. Cengage Learning Editores SA de CV, 2010. Acesso em: 02 dez. 2019.

CERQUEIRA, Ceres Aires. Dívida externa brasileira. Brasília: Banco Central do Brasil, 2003.

RAMBO, Andrea Carneiro. O perfil do investidor e melhores investimentos: da teoria à prática do mercado brasileiro. Monografia - Bacharel em Ciências Econômicas - Universidade Federal de Santa Catarina, Florianópolis, 2014. Disponível em: https://repositorio. ufsc. br/bitstream/handle/123456789/123812/M onografia\%20da\%20Andrea\%20Rambo.pd $\mathrm{f}$ ? sequence $=1 \&$ isAllowed $=\mathrm{y}$. Acesso em: 24 set. 2019.

RENNER, Marcio Cardoso. Teoria de portfólio de Markowitz em momentos de crise. Trabalho de Conclusão de Curso Especialização em Mercado de Capitais Universidade Federal do Rio Grande do Sul em parceria com a Apimec-Sul, Porto Alegre, 2010. Disponível em: https://www.lume.ufrgs.br/bitstream/handl e/10183/60625/000863146.pdf?sequence= 1. Acesso em: 08 set. 2019.

ROQUETTE, Inês Ulrica Araújo; LAUREANO, Raul; BOTELHO, Maria do Carmo. Conhecimento financeiro de estudantes universitários na vertente do crédito. Tourism \& Management Studies, v. 10, n. ESPECIAL, p. 129-139, 2014. Disponível em: http://www.scielo. mec.pt/pdf/tms/v10nEspecial/v10a16.pdf. Acesso em: 20 dez. 2019.
SANTOS, Laudiane de Jesus. Análise de estratégias de investimento na Bolsa de Valores no longo prazo. Monografia Graduação em Estatística - Curso de Estatística, Departamento de Estatística e Ciências Atuariais, Centro de Ciências Exatas e Tecnologia, Universidade Federal de Sergipe, São Cristóvão, 2019. Disponível em: https://ri.ufs.br/ bitstream/riufs/12211/2/Laudiane_Jesus_S antos.pdf. Acesso em: 16 dez. 2019.

SANTOS, José Odálio dos; SANTOS, José Augusto Rodrigues dos. Mercado de capitais: racionalidade versus emoção.

Revista Contabilidade \& Finanças, v. 16, n. 37, p. 103-110, 2005. Disponível em: https://www.scielo.br/pdf/rcf/v16n37/v16n 37a08.pdf. Acesso em: 06 out. 2019.

SILVA, Wesley Vieira; DEL CORSO, Jansen Maia; DA SILVA, Sandra Maria; DE OLIVEIRA, Eliane. Finanças comportamentais: análise do perfil comportamental do investidor e do propenso investidor. Revista Eletrônica de Ciência Administrativa, v. 7, n. 2, p. 1-14, 2008. Disponível em: http://www. periodicosibepes.org.br/index.php/recadm/ article/view/48/238. Acesso em: 25 maio 2019.

SIMONSEN, Mário Henrique. A inflação brasileira: lições e perspectivas. Revista de Economia Política, v. 5, n. 4, p. 15-30, 1985. Disponível em: http://www.rep.org. br/PDF/20-2.PDF. Acesso em: 19 ago. 2019.

SOARES, Maria Isabel et al. Decisões de Investimento: Análise Financeira de Projetos. Sílabo; $4^{\mathrm{a}}$ edição, revista e corrigida. 2015. Acesso em: 08 dez. 2019.

TAVARES, Adilson de Lima; SILVA, César Augusto Tibúrcio. A análise financeira fundamentalista na previsão de melhores e piores alternativas de investimento. Revista Universo Contábil, v. 8, n. 1, p. 37-52, 2012. Disponível em: https://proxy.furb.br/ojs/index.php/univers 
ocontabil/article/view/2309/1850. Acesso em: 29 dez. 2019.

TEIXEIRA, Vandliny Paiva Martins; DA CUNHA, Moisés Ferreira. Aplicabilidade dos modelos CAPM local, CAPM local ajustado e CAPM ajustado híbrido ao mercado brasileiro. In: Anais do

Congresso USP de Iniciação Científica em Contabilidade. 2017. Disponível em: https://congressousp.fipecafi.org/anais/Ana isCongresso2017/ArtigosDownload/134.pd f. Acesso em: 30 nov. 2019.

Tesouro Direto. Preços e taxas dos títulos IPCA, pré e pós fixados. Disponível em: https://www.tesourodireto.com.br/titulos/pr ecos-e-taxas.htm. Acesso em: 07 mar. 2020.

VELHO, Veralice do Carmo Faé. Análise do perfil do investidor do Banco Índice na Agência Paranhana. Trabalho de Conclusão de Curso - Bacharel em Administração - Universidade do Rio Grande do Sul, Porto Alegre 2010. Disponível em: https://lume.ufrgs.br/ bitstream/handle/10183/30241/000780297. pdf? sequence $=1 \&$ is Allowed $=y$. Acesso em: 07 abr. 2020.

ZIMNOCH, Gisele. Relação entre a taxa Selic e o índice Bovespa. Trabalho de Conclusão de Curso - Especialização em Finanças - Universidade do Rio Grande do Sul, Porto Alegre, 2012. Disponível em: https://lume.ufrgs.br/bitstream/handle/1018 3/83565/000906791.pdf?sequence $=1 \&$ isAl lowed=y. Acesso em: 11 fev. 2020. 